\title{
Development, implementation, and uptake of a novel CaRMS residency recruitment committee strategy in the era of COVID-19
}

Emily Nham ${ }^{1}$; Ravi Kumar ${ }^{2}$; Kristen McAlpine ${ }^{3}$; Christine Seabrook ${ }^{3}$; Marika Valle ${ }^{2}$; Isabel Menard $^{2}$; James Watterson ${ }^{1,2}$; Matthew Roberts ${ }^{1,2}$

${ }^{1}$ Faculty of Medicine, University of Ottawa, Ottawa, ON, Canada; ${ }^{2}$ Division of Urology, University of Ottawa, Ottawa, ON, Canada; ${ }^{3}$ Division of Urology, University of Toronto, Toronto, ON, Canada; ${ }^{3}$ Office of Education, Department of Surgery, University of Ottawa, Ottawa, ON, Canada

Cite as: Nham E, Kumar R, McAlpine K, et al. Development, implementation, and uptake of a novel CaRMS residency recruitment committee strategy in the era of COVID-19. Can Urol Assoc J 2022 January 27; Epub ahead of print. http://dx.doi.org/10.5489/cuaj.7676

Published online January 27, 2022

Corresponding author: Dr. Matthew Roberts, Division of Urology, University of Ottawa, Ottawa, ON, Canada; mroberts@toh.ca

$* * *$

\section{Abstract}

Introduction: Given restrictions on electives outside of medical students' home institutions during the COVID-19 pandemic, the objective of this study was to create a novel recruitment strategy for the University of Ottawa's (uOttawa) urology residency program.

Methods: A steering committee was formed and created a three-part recruitment strategy that included a new uOttawa urology website, a residency program social media campaign (Twitter and Instagram), and a virtual open house ( $\mathrm{VOH})$. Descriptive data from the website and Instagram and Twitter accounts were collected. Attendees of the VOH completed a mixedmethods survey, which collected quantitative and qualitive responses assessing aspects of the $\mathrm{VOH}$ and virtual resource use.

Results: From August 1 to December 31, 2020, the uOttawa urology website had 1707 visits. The Twitter account had a total of 29000 views with 1000-5000 views per tweet. Thirty-one candidates attended the VOH. Survey responders reported that the most frequently used resources to gain knowledge of the program were the website (81\%) and Twitter account (71\%). The most helpful and informative resources were the uOttawa urology website, the VOH, and direct conversations with residents arranged through the website. Despite not having completed an elective, 26 students (84\%) felt they had an understanding of what it might feel like to train in the program. Suggestions by students for future initiatives included one-on-one virtual meetings, another $\mathrm{VOH}$, and more information on selection processes. 
Conclusions: A multifaceted, virtual recruitment strategy can be implemented to improve candidate understanding and engagement with residency programs while visiting elective opportunities remain limited.

\section{Introduction}

The COVID-19 pandemic has posed many challenges for medical students in their final year of undergraduate training. On June 18, 2020, the Association of Faculties of Medicine of Canada (AFMC) declared the cancellation of visiting electives for medical trainees due to concerns with limited capacity at training sites, ongoing and evolving inter-provincial public health measures, and equity concerns. ${ }^{1}$ While this decision was put forward to reduce the COVID-19 risk to medical learners and communities, it also introduced significant challenges to both medical students and residency programs during the Canadian Resident Matching Service (CaRMS) interview and matching process. Visiting electives allow medical students to further explore different careers, experience the culture of a program, form relationships with residents and faculty, and visit prospective cities they may be living in during residency. Previous studies have found that workplace environment and geography are some of the most important considerations when selecting a residency program. ${ }^{2}$ Other factors influencing medical students' residency program rankings include program collegiality, quality of life of current residents, clinical and academic support, reputation of the program, resident case volumes, and quality of the curriculum. ${ }^{3,4}$ While certain objective information and program descriptions can be found on the CaRMS and university websites, other factors such as workplace environment, geography, and program collegiality may be better appreciated through first-hand experience.

For residency programs, visiting electives allow the staff and residents within a program to engage with potential future colleagues. A recent survey of the selection committees for Canadian Urology residency programs found that the most important selection criteria when ranking applicants was "clinical performance during a rotation at their school". ${ }^{5}$ Completing a rotation at the school and assessing the applicant was ranked as the fourth most important selection criteria in this survey. ${ }^{5}$ With the absence of visiting electives, residency programs are now tasked with the challenge of developing new CaRMS recruitment strategies. Residency programs' use of online meetings and social media websites such as Twitter and Instagram have increased, but their utility have not been well investigated. The objective of this study was to develop, implement, and assess the uptake of a novel residency recruitment committee strategy for the recruitment of final year medical students who were considering applying to urology during the 2021 CaRMS process.

\section{Methods}

A steering committee at the University of Ottawa (uOttawa) was created and included the program director, urology faculty members, resident representatives, and a program 
administrator. Meetings were held on a bi-weekly basis. The committee developed a 3-part recruitment strategy for the CaRMS 2021 match cycle. This strategy included: 1) the development of a residency program-specific website; 2) creation of a social media campaign via program-specific Twitter and Instagram accounts; and 3) hosting a virtual open house.

\section{Part 1: Website}

The goal of the website was to create a platform where medical students could easily access information about the program, faculty members, residents, upcoming events, resources, and could to submit questions. The website was created and managed by the resident representative on the recruitment committee using www.wix.com (a free online web-development platform). Information on the residency program, resident, fellow and faculty profiles, and photos were compiled from all urology residents, fellows and faculty added to the website by the resident representative on the recruitment committee. Analytics were collected from the website including number of visits, number of first-time users, number of users who visited the website more than once, number of questions submitted through the website and which links the website was accessed from (i.e. Twitter link, Instagram link, Google search, etc.)

\section{Part 2: Social media}

A social media campaign was launched to promote the online events held by the recruitment committee, to share resident and faculty profiles and pictures, and to highlight unique aspects of the residency program. This included creation of a new program-specific Twitter account managed by the resident representative and a faculty member on the recruitment committee and use of a pre-existing uOttawa Urology Instagram account managed by the same resident representative with assistance from other residents in the program. Content for the Twitter account was created around themes such as "a day in the life of a uOttawa urology resident", resident spotlights which shared information about one resident in the program, and upcoming online events. A preliminary post would be created and sent to the recruitment committee for review and approval. Instagram posts were created ad-lib from photos thought to highlight different aspects of the program. Data extracted from the Twitter account included "impressions" (defined as the number of times a tweet was viewed), "engagements" (defined as the number of times a tweet was clicked on by the user) and "engagement rate" (number of engagements/total number of impressions x 100) for each tweet. ${ }^{6}$ The number of Instagram posts and average number of likes per post was collected.

\section{Part 3: Virtual open house}

The primary purpose of the virtual open house was for candidates and programs to meet "faceto-face". The event was hosted on Zoom, an online platform where you can host virtual meetings with unlimited participants. On a Zoom call, individuals can turn their video and audio on and off, and can share their screen with other participants. Participants were required to register online prior to the open house and were given the opportunity to submit questions in advance. 
The agenda consisted of: 1) introductions from each attendee (medical students, residents, alumni and faculty); 2) introduction to the program by the program director; 3) highlights of uOttawa Urology by the resident representative on the recruitment committee; 4) resident perspectives from residents in each year of the program; 5) alumni perspective; 6) frequently asked questions (FAQ); and 7) a live question and answer (Q\&A) period.

Medical students who attended the virtual open house were asked to complete a 3-part online, anonymous survey (Appendix 1). The first part of the survey was designed to assess resource utilization and effectiveness. The resources in question were the CaRMS website, the uOttawa Urology website, the Twitter account, the Instagram account, the virtual open house and direct conversations with residents and/or faculty. The second part of the survey assessed different components of the virtual open house. The final part of the survey addressed future needs and any additional strategies that students believed would be helpful. A 5-point Likert scale was used for most questions and a free text section was included at the end to allow students to comment on any additional pertinent details (Appendix 1).

A proposal for research ethics board (REB) approval was submitted. It was deemed that the project fell within the context of quality initiative, quality improvement, quality assurance, and/or program evaluation. Therefore, a full review by the Ottawa Hospital Science Network Research Ethics Board was not required. A formal REB exemption letter was obtained.

\section{Results}

\section{Website}

A new website dedicated to the Urology residency program at uOttawa was created and can be accessed at "uottawaurology.com". The website included the following pages: Home, About Us, Faculty, Residents, CaRMS 2021 Info, Gallery, Resources, and Contact Us. From August $1^{\text {st }}$ 2020 to Dec $31^{\text {st }}, 2020$ the website had a total of 1,707 visits from 1,191 unique visitors. Daily traffic ranged from 10-20 visitors. There were 885 people who accessed the website from a google search, 399 by inputting the Uniform Resources Locator (URL) directly, and 350 who accessed the website from Twitter. The majority of visitors were from Canada, however there were many who accessed the website from the United States ( $\mathrm{n}=58)$, as well as from countries such as India $(\mathrm{n}=10)$, Australia $(\mathrm{n}=4)$, the Philippines $(\mathrm{n}=4)$, and United Kingdom $(\mathrm{n}=3)$. Social Media A new uOttawa Urology Twitter account was created. From August $1^{\text {st }}$ to December $31^{\text {st }}$, there were 29,000 impressions (the number of times a tweet was viewed). Individual tweets were viewed by $1,000-5,000$ users. The average engagement rate was $7.5 \%$. For context, brands with excellent Twitter marketing strive for engagement rates between 1-3\%. ${ }^{6-7}$ A pre-existing Instagram account created on March 3, 2020 was used. During the study period, there were a total of 14 posts with an average of 33 likes per post. A promotional video was posted on Instagram and had a total of 438 views during the study period. 


\section{Virtual open house}

On September $26^{\text {th }}, 2020$, uOttawa Urology hosted its first virtual open house that was two hours in duration and held on the Zoom platform. Residents from every year of residency training and faculty from each urologic subspecialty attended. There were 31 candidates who requested attendance via the Google Forms sign-up sheet and were provided with a link for the meeting.

\section{Survey results}

There was a $100 \%$ response rate to the online survey with all 31 virtual open house participants completing all survey questions. The majority of respondents were in their final year of undergraduate medical training and were applying to the 2021 cycle of CaRMS $(77 \%, n=24)$ with 6 attendees in medical school but not applying to the 2021 cycle of CaRMS (19\%) and 1 participant not in medical school (3\%).

All 31 candidates who requested attendance via the Google Forms sign-up sheet attended the virtual open house (100\%). Of the 31 respondents, only 5 were not following the University of Ottawa Urology program on Twitter or Instagram at the time of survey completion (16\%). The most commonly used resource was the uOttawa Urology website with 25 respondents using the website (81\%), 22 using Twitter (71\%), 19 using the CaRMS website (61\%), 16 using Instagram (52\%), 16 using direct conversations with residents (52\%), and 7 using direct conversations with faculty $(23 \%)$ (Figure 1). The resources that participants found the most useful and informative were the virtual open house and website (Figure 2). Other resources that students heavily relied on were the CaRMS website and direct conversations with residents which were sought out individually by applicants and available through the website.

Most students first heard about the virtual open house through Twitter ( $n=20,65 \%)$. A smaller proportion of students found out about the open house through the uOttawa website $(n=15,16 \%)$ or through Instagram $(n=3,10 \%)$ and one student emailed the program directly $(3 \%)$. The majority of participants strongly agreed that the online registration process was easy $(n=29,94 \%)$ and enjoyed having the opportunity to introduce themselves to the group at the beginning of the virtual session $(n=29,94 \%)$ (Figure 3). All 31 participants agreed that the information about the structure of the program and curriculum was useful and agreed that hearing the alumni perspective during the virtual session was informative (100\%). Of the 31 participants, 30 participants agreed or strongly agreed that the resident perspective was useful (97\%) with only one participant neither agreeing nor disagreeing (3\%). The majority of participants agreed that the information about the city of Ottawa was useful $(n=29,94 \%)$ as were the FAQ $(n=29,94 \%)$ and live Q\&A $(n=28,90 \%)$ portions of the virtual session. The 2-hour time allocation was thought to be sufficient by 27 of participants $(87 \%)$, although one respondent said it could have been longer (3\%) and another two respondents believed it could have been shorter $(6 \%)$.

Overall, all participants agreed that the virtual open house was useful and informative. A total of 26 of the 31 students agreed that despite not being able to complete a visiting elective, 
they had a sense of what it might feel like to work with the residents and staff at uOttawa Urology (84\%) (Figure 3).

When students were asked about future directions for the uOttawa Urology campaign, most students $(n=20,67 \%)$ requested one-on-one virtual meetings with uOttawa Urology faculty and residents to obtain additional information about the program. 8 students $(27 \%)$ requested a second virtual open house and $4(13 \%)$ students felt as though they did not require any additional information about the program. Additional information that participants hoped to learn from the virtual open house that was not covered in the presentations included how the Residency Program would be evaluating students in light of cancellation of visiting electives and how to stand out when applying to the program. Finally, in the narrative feedback on the survey, students reported wanting to learn more about current residents and highlighted the positive effect of having several residents, alumni and faculty present during the open house.

\section{Discussion}

In this study, we described and evaluated a novel multi-faceted CaRMS recruitment strategy that involved a dedicated website, program-specific accounts on Twitter and Instagram and a virtual open house to communicate with future applicants. While social media is a valuable and effective strategy to reach out to interested students, having a formal and dedicated website can provide students with a reliable and comprehensive source to learn more about the residency program. Of all resources, the virtual open house was determined to be the most useful and informative. In particular, statements from residents and recent graduates on their personal experiences and thoughts of the program was determined to be particularly useful to attendees and provided attendees with a sense of the work environment despite not being able to complete an elective. Ultimately, $84 \%$ of attendees felt like they had a sense of what residency would be like at uOttawa Urology despite the lack of clinical electives.

In the COVID-19 era, where medical students are no longer able to complete visiting electives, it is paramount that residency programs are flexible and able to think of innovative ways to reach out to potential candidates. Many residency programs already have an online presence through Twitter, Instagram and/or Facebook. Ensuring that these accounts are active and updated frequently is important because, based on our study, they are a commonly-used resource of information for potential applicants to residency programs. Furthermore, a formal website can provide more comprehensive and detailed information about the program beyond that of the standardized CaRMS or faculty websites. This benefit is likely to continue long term, even with the return of visiting electives in the future. Many residency programs use different platforms to release information about their program and this can be challenging for medical students to navigate, especially for students who are not active on social media. In response to this, the AFMC has recently released a 'Residency Program National Web Calendar' where residency program events can be found in one centralized location that is widely disseminated to learners. ${ }^{8}$ Programs should consider submitting any future CaRMS events such as virtual open 
houses to the AFMC National Web Calendar in addition to their own personal platforms to ensure accessibility by all students.

Virtual open houses are a useful way to highlight unique characteristics of the program and attract future applicants in a more dynamic manner. They also allow medical students across the nation to learn more about programs and interact with program members in a way that lowers costs, reduces travel and increases convenience and scheduling flexibility. ${ }^{9-11}$ When in-person electives were permitted, the uOttawa Urology program had an unlimited number of spots for elective students with an average of 25-30 visiting elective students and between 40-50 applicants to the program per year. These numbers are comparable to attendees of the virtual open house and applicants of the $2021 \mathrm{CaRMS}$ match suggesting that a virtual residency recruitment strategy may be a satisfactory alternative to in-person vising electives while restrictions on visiting elective remain in place. Some disadvantages of this approach however include limited understanding or misinterpretation of training environment, technical difficulties for applicants attempting to access the online resources and/or events, and unanticipated sources of bias. ${ }^{9}$ Some strategies that have been described to overcome some of the barriers faced by limited face-to-face contact include the creation of virtual electives and surgical skills workshops, online lecture series, mentorship programs, and initiatives targeted to increase diversity, equity and inclusion for under-represented applicants. ${ }^{12-18}$ In our study, we found that providing large group-sessions ensured equal access to information provided about the program and was necessary to maintain fairness during the CaRMS process. We suggest including current residents of all levels of training and former graduates of the program to speak about their experiences as this provides listeners with a diverse experiences and a direct representation of their careers as future urology trainees and alumni. The resident perspective has the added benefit of allowing attendees to meet future colleagues and develop interpersonal connections.

There are some limitations to our study. The purpose of our residency recruitment strategy was to increase engagement of future applicants and provide applicants with various virtual resources to learn about the uOttawa Urology program. Based on the narrative comments we received from medical students in our survey, students were concerned about how they would be evaluated and how to stand out amongst fellow applicants. Our study did not address these concerns and no information was included as part of the selection criteria. Clerkship electives have previously been perceived as job interviews by applicants and residency selection committees, ${ }^{8}$ and these perceptions may have affected our responses despite anonymity. Our responses could have also been inflated as our virtual open house was one of the first few held during the 2021 CaRMS application year. The concept of "Zoom fatigue" has been described and responses may have been less favorable with more frequent virtual sessions held. ${ }^{19}$ Additionally, this is a small study based on the strategies used at a single residency program. Further studies should compare the efficacy of different recruitment strategies and virtual open house formats and whether this effect is sustainable across multiple encounters.

\section{Conclusions}


We have developed a novel, multi-faceted recruitment strategy to facilitate knowledge transfer, virtual 'face-to-face' meetings and social media updates to ensure applicants to our residency program feel engaged and informed despite the cancellation of visiting electives. Our strategy was found to be valuable based on the number of applicants reporting use of each component of the strategy and satisfaction that they had a good understanding of what it would be like to train at uOttawa Urology. With the uncertainty of visiting electives for the upcoming 2022 match cycle, our strategy may be effectively utilized by programs moving forward to aid in residency recruitment. 


\section{References}

1. Afmcstudentportal.ca. AFMC Student Portal: COVID-19 Updates. [updated March 20 2021; cited March 20 2021]. https://www.afmcstudentportal.ca/covid-19. Accessed October 24, 2020.

2. Nuthalapaty FS, Jackson JR, Owen J. The influence of quality-of-life, academic, and workplace factors on residency program selection. Acad Med 2004;79:417-25.

3. Parker AM, Petroze RT, Schirmer BD, Calland JF. Surgical Residency Market Research-What Are Applicants Looking for? J Surg Educ 2013;70:232-6.

4. Stefanidis D, Miles WS, Greene FL. Factors Influencing Residency Choice of General Surgery Applicants-How Important Is the Availability of a Skills Curriculum? J Surg Educ 2009;66:325-9.

5. Nguyen D-D, Lee JY, Domes T, et al. Survey of Canadian urology programs: Which aspects of the Canadian Residency Matching Service (CaRMS) application are the most important? Can Urol Assoc J 2020;14:169-73.

6. Driskill J. Twitter Engagement Rate Calculator. The Online Advertising Guide. https://theonlineadvertisingguide.com/ad-calculators/twitter-engagement-ratecalculator/. Accessed Jan 2, 2022.

7. Quadros M. How to Increase Your Twitter Engagement Rate. Socialbakers.com. 2020 Nov 24. https://www.socialbakers.com/blog/twitter-engagement. Accessed Jan 2, 2022.

8. Afmc.ca. AFMC: 2021 R1 Match Resources. https://calendar.time.ly/ajrijxao/month. Accessed December 19, 2021.

9. Davis MG, Haas MRC, Gottlieb M, et al. Zooming In Versus Flying Out: Virtual Residency Interviews in the Era of COVID-19. AEM Educ Train 2020; 4:443-446.

10. Griffith M, DeMasi SC, McGrath AJ, et al. Time to Reevaluate the Away Rotation: Improving Return on Investment for Students and Schools. Acad Med. 2019;94:496500.

11. Satyan K., Arora S, Skipper B, et al. Randomized Evaluation of a Web Based Interview Process for Urology Resident Selection. J Urol. 2012;187:1380-4.

12. Nguyen DD, Reitblat CR, Andino JJ, et al. Virtual "matchmaking" without visiting electives: Overview of the early U.S. experience and potential applications to the 2021 Canadian urology match. Can Urol Assoc J 2020; 15:141- 3.

13. Kahn JM, Fields EC, Pollom E, et al. Increasing Medical Student Engagement Through Virtual Rotations in Radiation Oncology. Adv Radiat Oncol 2021; 6:100538.

14. Steehler AJ, Pettitt-Schieber B, Studer MB, et al. Implementation and Evaluation of a Virtual Elective in Otolaryngology in the Time of COVID-19. Otolaryngol Head Neck Surg 2021;164:556-61.

15. Alameddine MB, Englesbe MJ, Waits SA. A Video-Based Coaching Intervention to Improve Surgical Skill in Fourth-Year Medical Students. J Surg Educ 2018;75:14759.

16. Chao TN, Frost AS, Brody RM, et al. Creation of an Interactive Virtual Surgical Rotation for Undergraduate Medical Education During the COVID-19 Pandemic. $J$ Surg Educ 202;78:346-350. 
17. Dedeilia A, Sotiropoulos MG, Hanrahan JG, et al. Medical and Surgical Education Challenges and Innovations in the COVID-19 Era: A Systematic Review. In Vivo 2020; 34:S1603-11.

18. Porpiglia F, Checcucci E, Amparore D, et al. Slowdown of urology residents' learning curve during the COVID-19 emergency. BJU Int 2020;125:15-7.

19. Wiederhold BK. Connecting Through Technology During the Coronavirus Disease 2019 Pandemic: Avoiding "Zoom Fatigue". Cyberpsychol Behav Soc Netw 2020;437-438.

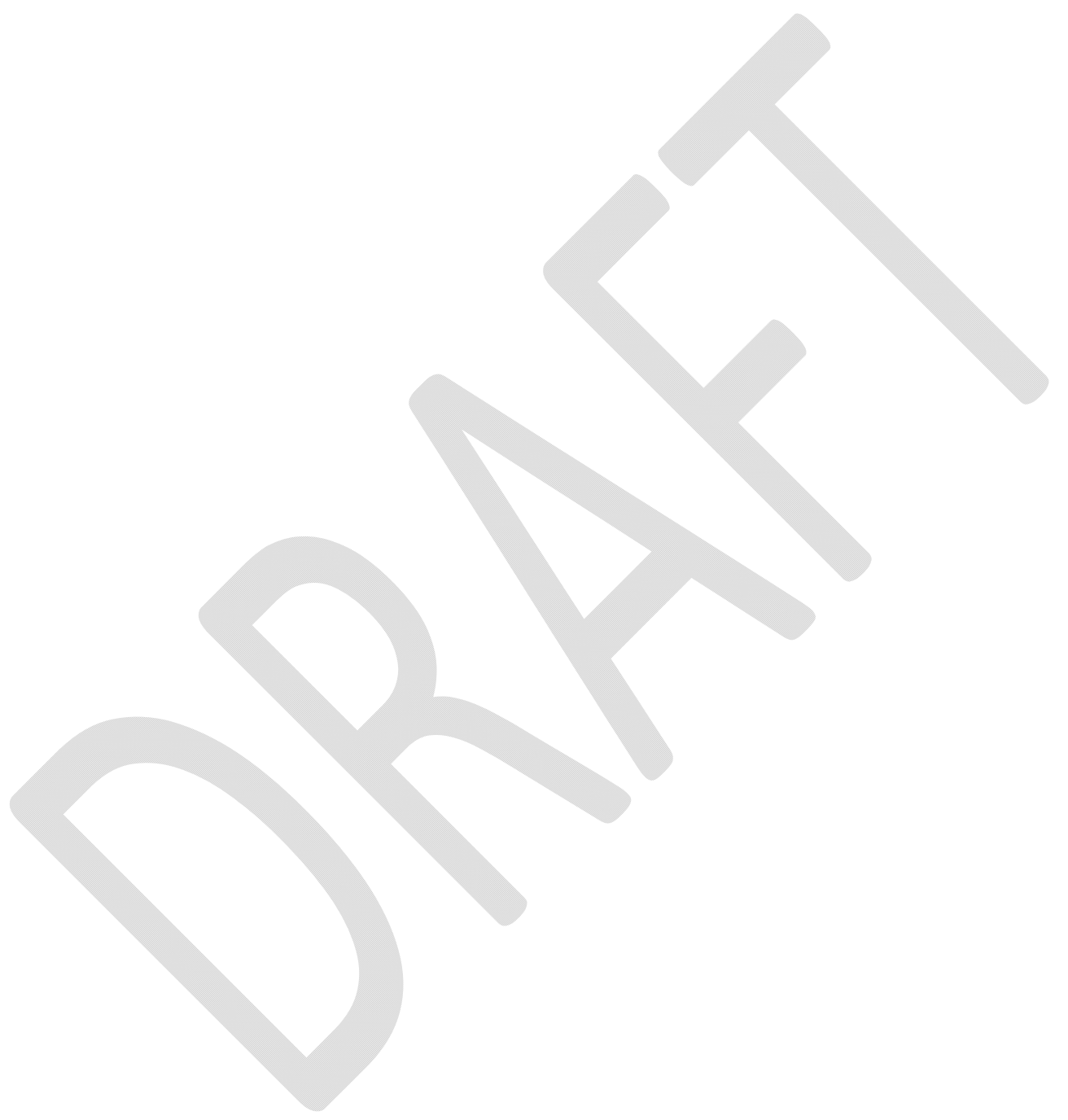




\section{Figures and Tables}

Fig. 1. Resource utilization by medical students to gain information about the University of Ottawa's urology residency program (Question 2).

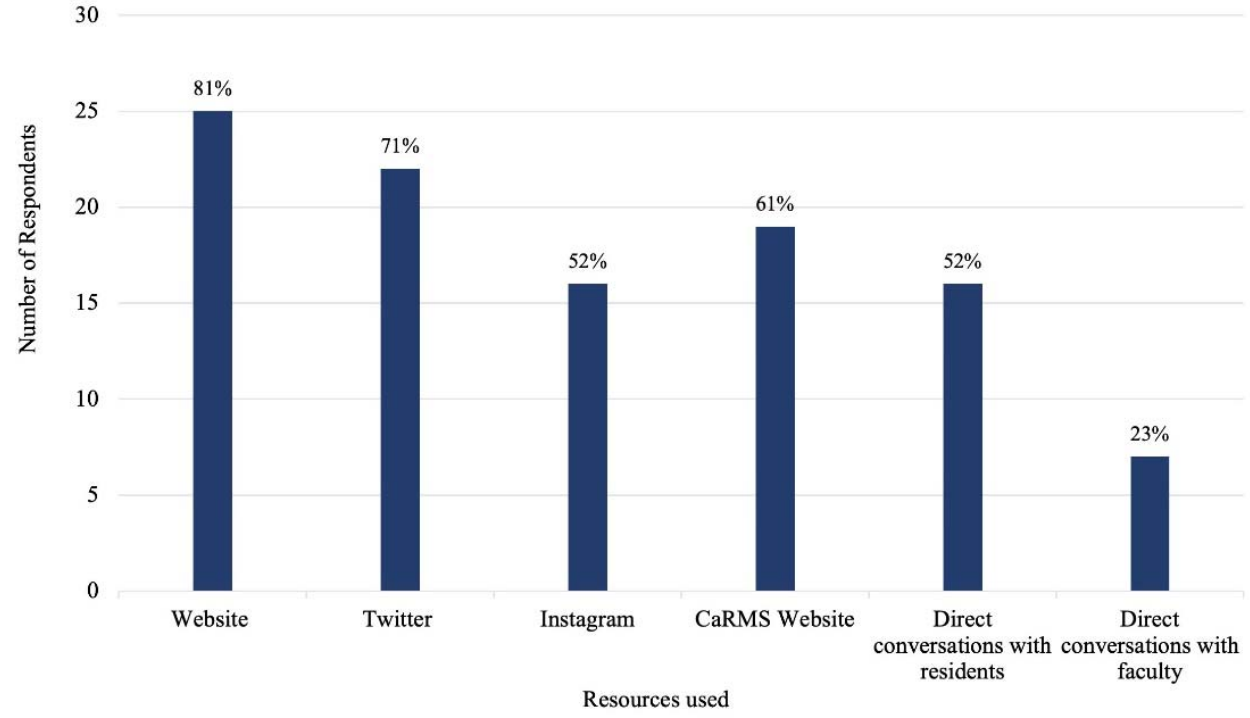

Fig. 2. Medical students' response of resource found to be helpful when obtaining information about the University of Ottawa's urology residency program (Question 6).

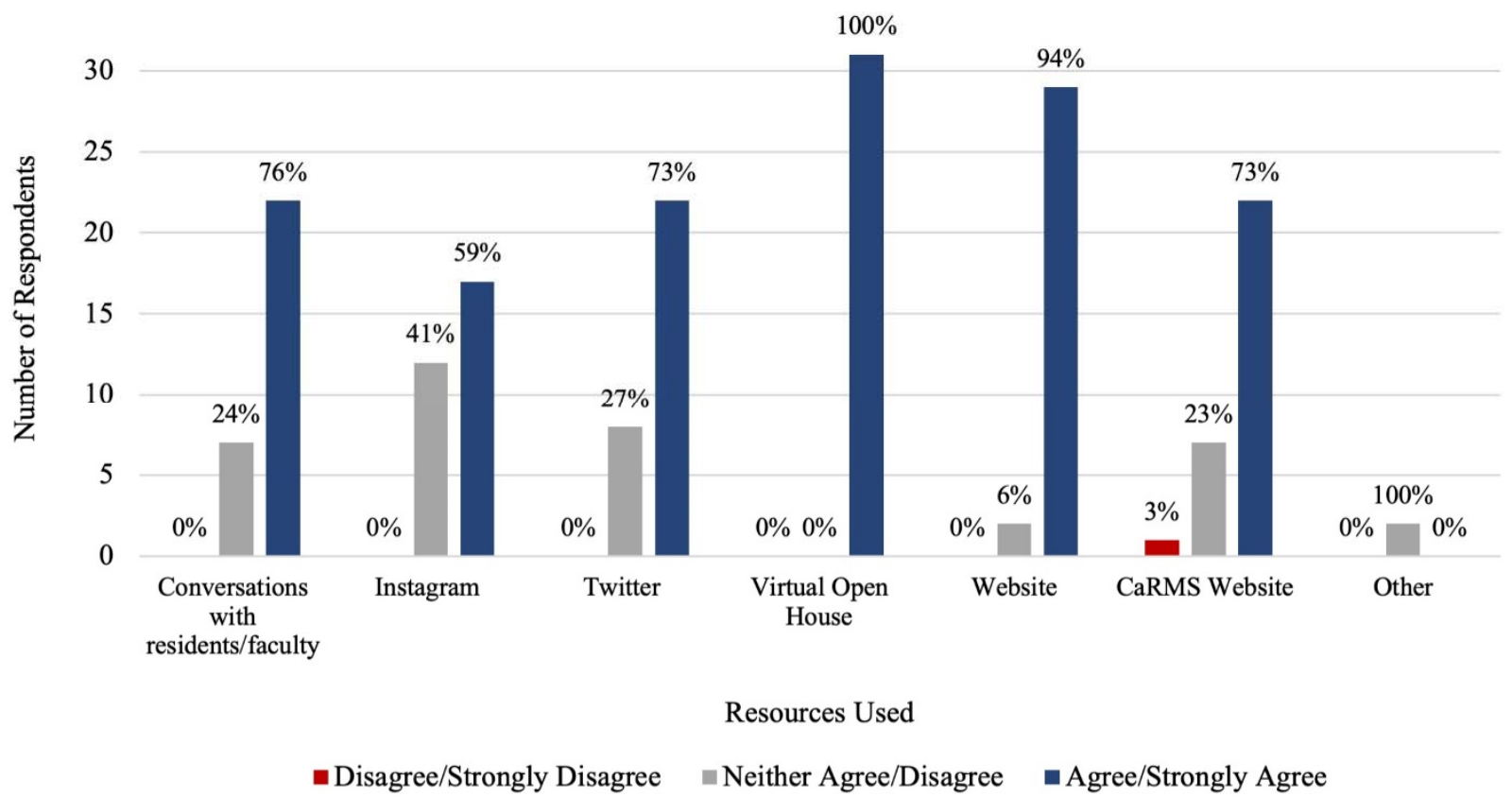


Fig. 3. Medical students' perspectives on the ease, structure, and utility of the University of Ottawa's urology virtual open house.

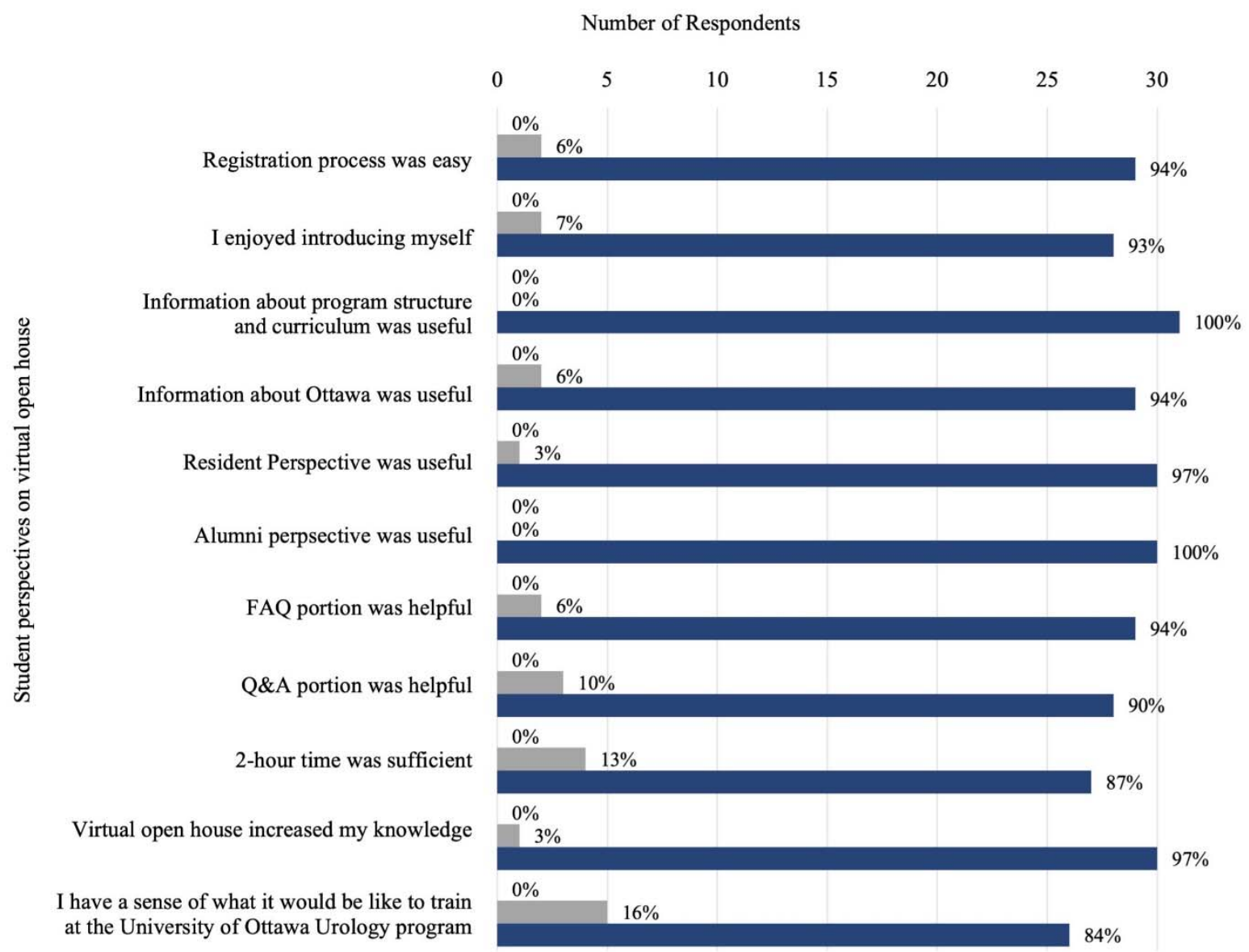

-Disagree/Strongly Disagree $=$ Neither Agree/Disagree $\quad$ Agree/Strongly Agree

Legend:

$\mathrm{FAQ}=$ frequently asked questions; $\mathrm{Q} \& \mathrm{~A}=$ question and answer. 